\title{
Full Factorial Design of Screening Experiments for Biosurfactant Enhanced Remediation of Hydrophobic Substances in Soil
}

\author{
L. Timma, K. Sams, S. Valtere, J. Vilgerts, and D. Blumberga
}

\begin{abstract}
This paper evaluates the cleaning efficiency of glycolipid-based anionic biosurfactant produced by a local company. Before practical application in removal of oil or other hydrophobic substances from soil, it is necessary to learn the behavior of the biosurfactant across different systems. As process variables, temperature of environment, contact time with dilution of biosurfactant, and concentration of biosurfactant in washing solution were modeled by applying full factorial design. As response variable, cleaning efficiency was obtained experimentally by a set of laboratory tests. Screening design is employed for evaluation of interactions between response variable and process variables. The cleaning efficiency showed various results depending on the initial values of variables. At the upper limit of variables $\left(+35^{\circ} \mathrm{C}\right.$ temperature of environment, 15 minutes contact time with dilution of biosurfactant, and $0.3 \mathrm{wt} \%$ concentration of biosurfactant in washing solution) the cleaning efficiency was $99.32 \%$. The results showed that all variables had significant effects on the cleaning efficiency at $95 \%$ confidence level.
\end{abstract}

Index Terms-Biosurfactant, cleaning efficiency, design of experiment, full factorial design, hazardous waste, soil washing.

\section{INTRODUCTION}

Wide application and improper disposal of oil products and other hazardous waste, as well as accidents related to them result in long-lasting contamination of soil and subsurface environment. Contamination inevitably will affect ecosystems and human health. Although the clean-up work is conducted in situ and on site, the state of development among different technologies varies widely-from fundamental research to commercial products and processes.

One of feasible ways to remove contamination from soil is bioremediation. Nevertheless, utilization of plants or microorganisms to convert pollutants to the carbon dioxide and water often is time consuming and is not cost effective for large quantities of soil or high concentration of pollutants. In case of highly toxic substances (bacterocides) bioremediation is entirely impossible. Therefore, one of the alternative methods is soil washing, which can be done faster and can be applied for large amounts of pollutant.

The penetration of oil or other waste products in soil

Manuscript received April 15, 2013; revised July 2, 2013.

L. Timma, S. Valtere, J. Vilgerts, and D. Blumberga are with the Institute of Energy Systems and Environment, Riga Technical University, Riga, Latvia, LV-1010 (e-mail: lelde.timma@rtu.lv; sarma.valtere@rtu.lv; janis.vilgerts@rtu.lv; dagnija.blumberga@rtu.lv).

K. Sams is with the company "Auravia Latvia" SIA, Riga, Latvia, LV-1004 (e-mail: karlis.sams@auravia.lv). depends on biological, chemical, and physical factors, therefore, it involves complex mechanisms. The hydrophobic nature of oil products limits their availability for microorganisms, thus lowering the effectiveness of bioremediation processes. In order to increase the rate of desorption, solubilization, and to facilitate the bioavailability of hydrophobic pollutants, surfactants are used.

Studies show that synthetic surfactants tend to be toxic and resistant to biodegradation [1], [2]. In the result, research on environmentally sound surfactants - biosurfactants increased significantly between 2000 and 2010 [3]. Biosurfactants can be composed biologically by fermentation, by cell growth of microorganisms, and by bioconversion carried out via enzymes synthesized by bacteria or yeast (microbial cultivation) or from substances such as sugars, oils, alkanes, etc. (chemical synthesis). Bio-based surfactants are obtained also by transesterification of fats or derived from plants or animal fat via saponification. Biosurfactants synthesized by microorganisms can be grouped into 6 major classes based on the microorganism: glycolipids, phospholipids, polysaccharide-lipid complexes, lipoproteins-lipopeptides, hydroxylated and cross-linked fatty acids. In comparison with synthetic surfactants, biosurfactants have better surface activity, lower toxicity, they can bind heavy metals, have higher biodegradability, and biological activity, they are produced from renewable resources and can be reused by regeneration [4]-[6]. Other advantages of biosurfactants are that there is no need to remove biosurfactants from effluents during soil washing, as their release will not damage the environment [1].

Properties of surfactants can be estimated by their net charge, structure, and hydrophilic-lipophilic-balance value (HLB). Apart from chemical and physical characterization, performance indicators also includes: haptic properties of surfactant, foaming abilities, odor and colour [3].

Cleaning efficiency of solution of surfactants depends on the parameters of surfactant, surrounding environment, and properties of pollutants. Therefore, the classical studies on the interaction between various factors affecting the cleaning efficiency of surfactants often are expensive, time-consuming, and performed under simplified conditions (for example, a sample of soil consisting of single fraction). Besides, some interactions have non-linear nature.

Under the conditions given, application of statistical data analysis tools presents an effective way for the optimization of process parameters. One of the first steps in the design of experiment is screening design. The screening design is used before optimization and robustness tests are performed. 
Within the screening design, interaction polynomials are used employing a factorial design.

The method of factorial design requires few runs per investigated parameter, allows identifying influential process parameters without time consuming and costly tests. Also regression model presents the nature of interconnection between process variables at high confidence level. The model can be upgraded to form composite designs. The results can be presented as 2- and 3-dimensional charts, thus factorial design has great practical value at early stages of a project [7].

References on the application of factorial screening design in the field of biosurfactants can be found in the area of process optimization for biodegradation of ethyl benzene and xylene compounds in mixtures [8], for efficiency increase in the removal of total petroleum hydrocarbons [9] and diesel [10], for location of the most suitable temperature and surfactant concentration [11] and for determination of recovery efficiency of enzymes [12].

Bioremediation technology becomes even more sustainable in case when raw materials for technological processes are not only renewable, but also available and produced locally. This paper evaluates the cleaning efficiency of glycolipid-based anionic biosurfactant produced by a local company.

Nevertheless, before practical application in removal of oil or other hydrophobic substances from soil, it is necessary to learn the behavior of biosurfactant across different systems. As process variables, temperature of environment, contact time with dilution of biosurfactant, and concentration of biosurfactant in washing solution were modeled by applying full factorial design. As response variable, cleaning efficiency was obtained experimentally by a set of laboratory tests. Screening design is employed for evaluation of interactions between response variable and process variables.

\section{MATERIALS AND Methods}

Within the research, the interactions between 3 independent variables: temperature of environment $\left({ }^{\circ} \mathrm{C}\right)$, contact time with dilution of biosurfactant (minutes), and concentration of biosurfactant in washing solution (\% by weight (wt \%)) were analyzed. As response (dependent variable), cleaning efficiency (\%) was obtained experimentally by a set of the laboratory tests.

\section{A. Full Factorial Design of Experiments}

For this research, factorial design for experimental data was chosen, because the design allows determination of factors with the highest impact on the process. Full factorial design of $2^{\mathrm{k}}+\mathrm{k}$ runs, where $\mathrm{k}$ is the number of variables, was selected for the screening design. The full factorial screening design involves runs at every possible combination at the defined upper and lower limit for each variable, see Table I. To the matrix of design, additional centrepoints (set of 3 experiments at the same conditions) were added, see Table I.

The upper and lower values of variables have been chosen to mimic the actual soil washing facility. As pointed out by the reference [13], a time-efficient treatment test should take a couple of minutes rather than hours.
TABLE I: DESIGN MATRIX OF THE EXPERIMENT

\begin{tabular}{|c|c|c|c||}
\hline Parameter & $\begin{array}{c}\text { Upper } \\
\text { limit }\end{array}$ & $\begin{array}{c}\text { Lower } \\
\text { limit }\end{array}$ & Centrepoint \\
\hline Temperature, ${ }^{\circ} \mathrm{C}$ & +35 & +30 & +32 \\
\hline Contact time, min. & 15 & 5 & 10 \\
\hline $\begin{array}{c}\text { Biosurfactant concentration, } \\
\mathrm{wt} \%\end{array}$ & 0.3 & 0.1 & 0.2 \\
\hline
\end{tabular}

In total, 11 experiments were made $\left(2^{3}\right.$ for variables, and 3 at the centrepoint). As output of factorial screening tests, the key interactions between all variables are given. The resolution of experimental data is set to 3 -factor and higher interactions between variables. Cubic interaction between the variables has been set as the initial model for process factors. The validity of the model is verified by the analysis of values in the ANOVA table. The predication limit is set to $95.0 \%$. The interactive statistical data analysis tool STATGRAPHICS Centurion 16.1.15 was used to construct the model for factorial screening design.

\section{B. Preparation of Samples}

The experimental oily stain was composed from rapeseed oil (94 wt \%), carnauba wax (5.5 wt \%), and Sudan red 7B (0.5 wt \%). The stain mixture was prepared by warming up rapeseed oil up to $100{ }^{\circ} \mathrm{C}$, then carnauba wax was added to the mixture. After the wax had melted completely, Sudan red 7B (dye content $95 \%$, by ALDRICH Chemistry) was added in small quantities and mixed till complete dissolution. The total volume of the stain mixture needed for all experiments (including calibration) was prepared at once.

After the prepared stain mixture was cooled down to $50{ }^{\circ} \mathrm{C}$, the mixture was applied on stainless steel plates $(40 \times 20 \times 3$ $\mathrm{mm}$ ) with a fine brush. The stainless steel plates had been weighed before the mixture was applied on them. The stain mixture was applied on the plates in several layers. In order to facilitate solidification of stain mixture on the plates, a time interval was ensured between applications of each following layer of the mixture. The prepared plates were held in an exsiccator at room temperature approximately for 30 minutes until complete cooling and weighted afterwards.

\section{Biosurfactant Used}

Blend of glycolipid-based anionic biosurfactant with the commercial name AURA-PURE ST (produced by the company "AURAVIA LATVIA"SIA, Latvia) was used in this research. The biosurfactant was purchased as $5 \mathrm{wt} \%$ solution with $\mathrm{pH}$ value of 10 . The critical micelle concentration (CMC) was $0.1 \%$ (surface tension- $27 \mathrm{mN} / \mathrm{m}$ ) and the hydrophilic-lipophilic balance (HLB) was 10 .

\section{Washing Method}

After been weighted, each stainless steel plate was placed on a stand made from stainless steel wire. The stand was used in order to avoid mechanical damage of the stain (contact between the stain surface and walls of the beaker) while washing of the samples is performed. Than each plate was immersed in a shallow beaker $(500 \mathrm{~mL})$ filled with $200 \mathrm{~mL}$ biosurfactant dilution. The biosurfactant dilution had been previously heated in water bath (BWT-U, BIOSANSIA, Latvia) till a constant temperature (accordingly to the values given in the row "Temperature" in the Table I) was reached. 
Immediately after the plate had been immersed, mechanical stirring (100 rpm) was applied using an overhead mixer equipped with 2 folded propeller stirrers (MM-1000, BIOSANSIA, Latvia). The time of mechanical stirring was altered for each test sample accordingly to the values given in the row "Contact time" given in the Table I. After the washing, plates were removed from the beaker and dried at room temperature.

\section{E. Analytical Method}

Quantitative data about cleaning efficiency was obtained through interpretation of measurements done with a UV spectrophotometer (UNICAM HE $\lambda$ IOS $\gamma$ ). Before the experiments, measuring range and calibration curve for the UV spectrophotometer were obtained. The calibration was performed for concentration of stain mixture from 0 to 0.15 $\mathrm{wt} \%$.

After the washing with surfactant and drying, the plates were placed in a shallow form beaker $(150 \mathrm{~mL})$ and rinsed with $25 \mathrm{~mL}$ of $99 \%$ chloroform (Sigma-Aldrich) for 5 minutes until complete dissolution of the stain mixture was achieved. The amount (concentration) of the stain mixture in chloroform solution was evaluated by colorimetric method. The absorbance intensities at $415 \mathrm{~nm}$ were compared with the predefined calibration curve.

The basic principles of the experimental methodology are borrowed from the Reference [14].

\section{RESULTS AND DISCUSSION}

\section{A. Statistical Validity of the Model}

Results of data analysis show that cubical interactions between the parameters have not been observed at $95.0 \%$ confidence level. Therefore, cubical interaction model was simplified to quadratic one. The general form of the quadratic model is

$$
y=\beta_{0}+\beta_{1} x_{1}+\beta_{2} x_{2}+\beta_{11} x_{1}^{2}+\beta_{22} x_{2}^{2}+\beta_{12} x_{1} x_{2}+\ldots+\varepsilon(1)
$$

where $y$ is the predicted response, $\beta_{0}$ is a constant, $\beta_{1}, \beta_{2}$ are linear coefficients, $\beta_{11}, \beta_{22}$ are second order coefficients, $\beta_{12}$ is an interaction coefficient, $x_{1}, x_{2}$ are variables, and $\varepsilon$ is a constant representing noise [7].

Estimates of P-value for the quadratic model are $>0.05$, therefore the model can describe experimental data at $95.0 \%$ confidence level. The same results about quadratic relationships between the process variables have been reported for the removal efficiency of total hydrocarbons from soil by nonionic surfactant in the Reference [9].

The R-Squared statistic indicates that the model as fitted explains $99.0845 \%$ of the variability in cleaning efficiency. The adjusted R-squared statistic, which is more suitable for comparing models with different number of independent variables, is $96.9484 \%$. It is important to examine Durbin-Watson statistic, since it can indicate the dependence between successive observations (drift over the experimental data). Since the Durbin-Watson statistic is 2.53323 at $\mathrm{P}=0.5652$, the serial autocorrelation in residuals is not observed at $5 \%$ significance level.

\section{B. Pareto Analysis}

Pareto chart shows effects of each variable on the absolute values for cleaning efficiency, see Fig. 1.

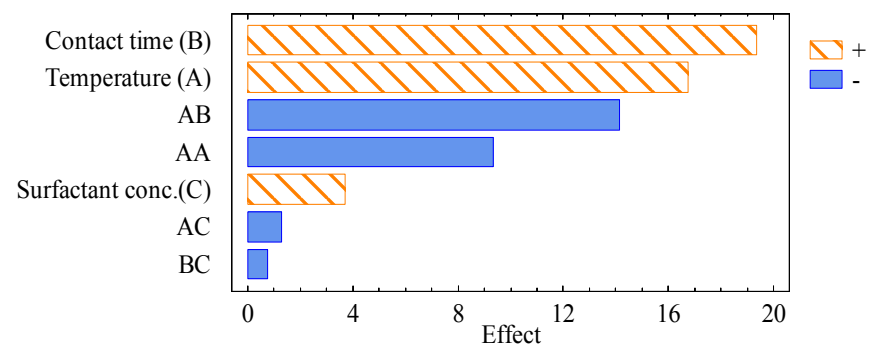

Fig. 1. Pareto chart (unstandardized form) for cleaning efficiency.

The colour of the bars depicts either effect of the variable on the cleaning efficiency is positive or negative. Fig. 1 shows that the most influential variables are temperature of environment and contact time with dilution of biosurfactant.

The standardized Pareto chart gives summary for variables in the order of absolute magnitude. The effect of each variable is converted to t-statistic by dividing the value of variable by its standard error, see Fig. 2.

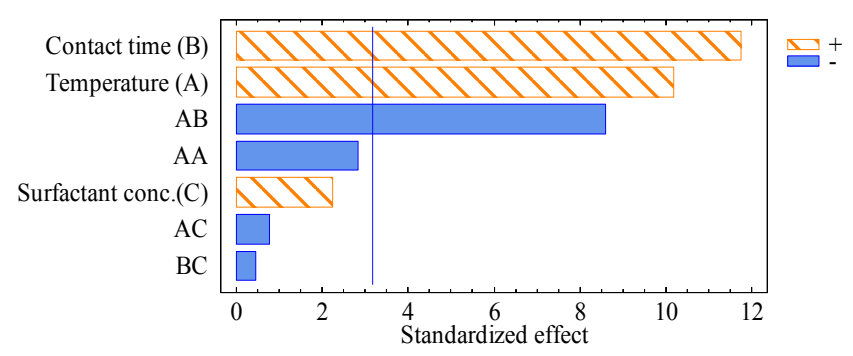

Fig. 2. Standardized Pareto chart for cleaning efficiency.

The blue line represents statistically significant variables at the significance level of $5 \%$. As can be seen from Fig. 2, increasingly significant is contact time and temperature, as well as the interaction of the both variables. Below the $5 \%$ significance level is the concentration of biosurfactant and all effects involving interaction with this variable.

\section{Half-Normal Probability Plot}

Another test to validate the effects of variables (excluding the impact of degrees of freedom) is the half-normal probability plot for variables, see Fig. 3.

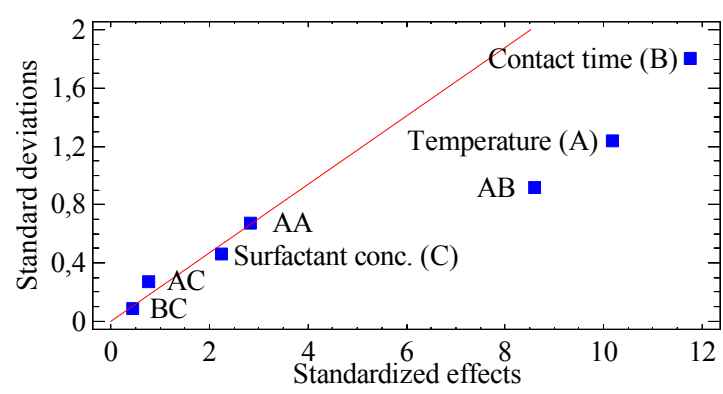

Fig. 3. Hhalf-normal probability plot for cleaning efficiency.

The advantage of the probability plot is in the arrangement of effects from variables on the "noise" line (red line in the Fig. 3). The more distant variable is from the "noise" line, the greater effect on the cleaning efficiency with higher accuracy 
can be obtained.

Fig. 3 confirms the conclusion of Fig. 1 and Fig. 2 that 3 significant factors are present in the model.

The antagonistic and synergistic interfaces between the variables have been revealed statistically by the Pareto plot and half-normal probability plot analysis. The results revealed that interaction between the concentration of biosurfactant and other parameters (AC and BC in Fig. 3) is below the $5 \%$ significance level.

\section{Revised Design of the Model}

From the Pareto chart and half-normal probability plot for variables, it is evident that the structure of the model can be simplified. The terms $\mathrm{BC}$ and $\mathrm{AC}$ are not statistically significant and are excluded from the further model.

For the final version of the model the following empirical equation for cleaning efficiency is obtained:

$$
\begin{aligned}
& \eta_{c l}=-1013.94+57.6467 t+20.3275 \tau+ \\
& +18.487 c-0.74825 t^{2}-0.5659 t \cdot \tau
\end{aligned}
$$

where $\eta_{c l}$ is cleaning efficiency, $\%, t$ is temperature, ${ }^{\circ} \mathrm{C}, \tau$ is contact time, minutes, and $c$ is concentration of the biosurfactant, wt \%.

The revised model in the form of the standardized Pareto chart is given in Fig. 4.

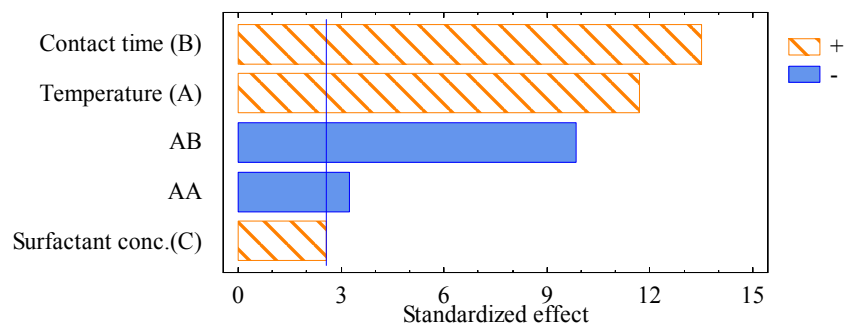

Fig. 4. Standardized Pareto chart for cleaning efficiency for the revised model.

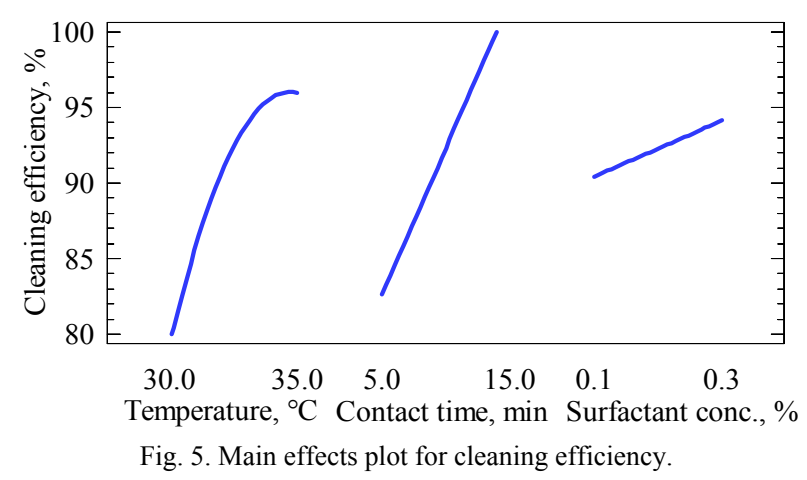

\section{E. Main Effects and Interaction Plots}

The empirical eq. (2) can be visually depicted by the main effect plot for cleaning efficiency, see Fig. 5.

The main effects plot shows how each of the analyzed responses changes within the boundaries of the stated upper and lower limit values. Fig. 5 shows that increase in the absolute values for all variables stimulated raise in cleaning efficiency. Nevertheless, gradient for temperature of environment and contact time with the dilution of the biosurfactant was steeper than for the concentration of biosurfactant in washing solution.

The main interaction within the model is observed between temperature and contact time, so the interaction plot is given in Fig. 6.

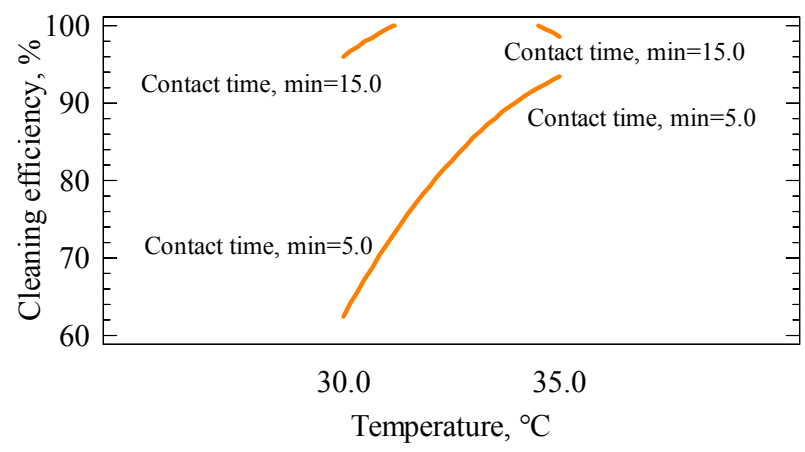

Fig. 6. Interaction plot for cleaning efficiency.

The interaction between temperature of environment and contact time with the dilution of biosurfactant has non-linear nature, see Fig. 6.

Temperature increase has greater impact on the cleaning efficiency at short contact times. The opposite is also true, at longer contact times, the influence of the temperature level losses its importance. The positive effect of elevated temperature on soil washing has been reviewed also by the Reference [15].

\section{F. Response Plots}

At the upper limit of variables (temperature of $35^{\circ} \mathrm{C}, 15$ minutes contact time, and $0.3 \mathrm{wt} \%$ concentration of biosurfactant), the cleaning efficiency obtained experimentally was $99.32 \%$. In Fig. 7, the empirical eq. (2) is shown in 3-dimensional space.

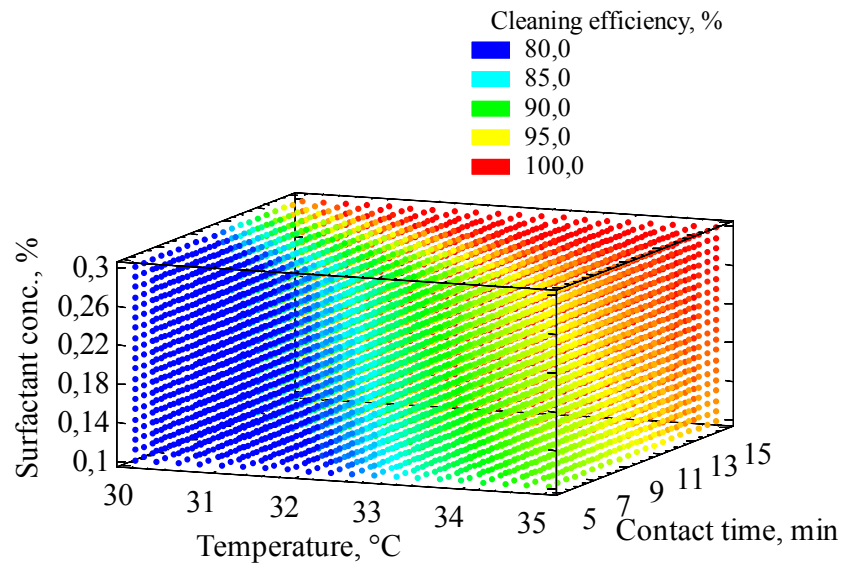

Fig. 7. Response plot for cleaning efficiency in 3-dimensional space.

The validation of the tests leads to corroboration of several practical observations. Temperature and contact time play a major role in the cleaning efficiency.

The concentration of detergent solution also could be a relevant parameter, but the impact of concentration usually is quite complex. As the concentration of surfactant increases, monomers aggregate to form micelles. The concentration at which micelles begin to form at the first time is known as the critical micelle concentration (CMC). The CMC corresponds to the point where the surfactant shows the lowest surface tension for the first time, too. Generally, the increase in 
temperature decreases the $\mathrm{CMC}$ of some non-ionic surfactants, but increases solubility of ionic surfactants.

Many physical properties used to characterize surfactants depend on the $\mathrm{CMC}$, such as emulsion formation, oil solubilization, foaming and detergency, interfacial and surface tensions. These properties may be used to assess the suitability of surfactant for environmental bioremediation, such as soil washing.

\section{CONCLUSION}

Photo colorimetric method is used in this research for determination of cleaning efficiency instead of the generally used gravimetric assessment.

The experimental tests showed high reliability for the assessment of degreasing and therefore are especially suited for exploration and optimization of different surfactants and their mixes.

The experimental test is easy to set up, highly sensitive, and can be adapted to solve the problems encountered by developers of detergent cleaners for better degreasing properties.

These experiments suggest that utilizing surfactants to increase the solubility of dense organic pollutants can be an effective and relatively inexpensive way of ex situ remediation of contaminated soils and aquifers.

The screening design was employed for the evaluation of interactions between the response variable and process variables. The cleaning efficiency showed various results depending on the initial values of variables. At the upper limit of variables $\left(+35{ }^{\circ} \mathrm{C}\right.$ temperature of environment, 15 minutes contact time with dilution of biosurfactant, and 0.3 wt $\%$ concentration of biosurfactant in washing solution), the cleaning efficiency was $99.32 \%$.

The results showed that all variables had significant effects on the cleaning efficiency at $95 \%$ confidence level.

Antagonistic and synergistic interfaces between the variables have been revealed statistically through full factorial design and by application of the Pareto plot and half-normal probability plot analysis. The results revealed that interactions between the concentration of biosurfactant in washing solution and other parameters is below the $5 \%$ significance level and thus can be removed from the regression model.

Increase in values for all variables stimulated increases in the cleaning efficiency. Nevertheless, the main effects plot shows that gradient for temperature of environment and contact time with dilution of biosurfactant was steeper than for the concentration of biosurfactant in washing solution.

The main interaction within the model is observed between temperature of environment and contact time with dilution of biosurfactant. The interference has non-linear nature. Temperature increase has greater impact on the cleaning efficiency at short contact times. The opposite is also true, at longer contact times, the influence of temperature level losses its importance.

The next phase of the experiments will be remediation of polluted soil with glycolipid-based anionic biosurfactants.

\section{REFERENCES}

[1] D. P. Sachdev and S. S. Cameotra, "Biosurfactants in agriculture," Applied Microbiology and Biotechnology, vol. 97, pp. 1005-1016, Feb. 2013.

[2] R. Marchant and I. M. Banat, "Microbial biosurfactants: challenges and opportunities for future exploitation," Trends in Biotechnology, vol. 30, pp. 558-565, Nov. 2012.

[3] M. M. Müller, J. H. Kügler, M. Henkel, M. Gerlitzki, B. Hörmann, M. Pöhnlein, C. Syldatk, and R. Hausmann, "Rhamnolipids-next generation surfactants?" Journal of Biotechnology, vol. 162, pp. 366-380, June 2012.

[4] T. Pekdemir, M. Copur, and K. Urum, "Emulsification of crude oil-water system using biosurfactant," Process Safety and Environmental Protection, vol. 83, pp. 38-46, 2005.

[5] I. N. A. Van Bogaert, K. Saerens, C. D. Muynck, D. Develter, W. Soetaert, and E. J. Vandamme, "Microbial production and application of sophorolipids," Applied Microbiology and Biotechnology, vol. 76, pp. 23-34, Aug. 2007.

[6] P. Vatsa, L. Sanchez, C. Clement, F. Baillieul, and S. Dorey, "Rhamnolipid biosurfactants as new players in animal and plant defense against microbes," International Journal of Molecular Sciences, vol. 11, pp. 5095-5108, Dec. 2010.

[7] L. Eriksson, E. Johansson, N. Kettaned-Wold, C. Wikstrom, and S. Wold, Design of Experiments, Principles and Applications, $3^{\text {rd }}$ revised and enlarged ed. Umea, Sweden: Umetrics, 2008, ch 3, pp. 53-100.

[8] E. R. Rene, M. S. Jo, S. H. Kim, and H. S. Park, "Statistical analysis of main and interaction effects during the removal of BTEX mixtures in batch conditions using wastewater treatment plant sludge microbes," Int. J. Environ. Sci. Tech., vol. 4, pp. 177-182, 2007.

[9] A. Kalali, T. Ebadi, A. Rabbani, and S. S. Moghaddam, "Response surface methodology approach to the optimization of oil hydrocarbon polluted soil remediation using enhanced soil washing," Int. J. Environ. Sci. Tech, vol. 8, pp. 389-400, Spring 2011.

[10] L. Molina-Barahona, R. Rodrıguez-Vázquez, M. Hernández-Velasco, C. Vega-Jarquin, O. Zapata-Pérez, A. Mendoza-Cantú, A. Albores, "Diesel removal from contaminated soils by biostimulation and supplementation with crop residues," Applied Soil Ecology, vol. 27, pp. 165-175, 2004.

[11] D. Goswami, R. Sen, J. K. Basu, and S. De, "Surfactant enhanced ricinoleic acid production using Candida rugosa lipase," Bioresource Technology, vol. 101, pp. 6-13, Jan. 2010.

[12] F. A. Hasmann, A. Pessoa, and I. C. Roberto, "Beta-Xylosidase recovery by reversed micelles. Use of cationic surfactant," Applied Biochemistry and Biotechnology, vol. 84-86, pp. 1101-1111, 2000.

[13] A. Uhmann and T. J. Aspray, "Potential benefit of surfactants in a hydrocarbon contaminated soil washing process: Fluorescence spectroscopy based assessment," Journal of Hazardous Materials, vol. 219-220, pp. 141-147, April 2012.

[14] A. Fitzner and U. Aßmus, "Recommendation for the quality assessment of the product performance of all-purpose cleaners degreasing efficiency according to internal test closed to IKW guideline," Journal SÖFW, vol. 131, pp. 54-66, Sep. 2005.

[15] K. Elgh-Dalgren, Z. Arwidsson, A. Camdzija, R. Sjöberg, V. Ribé, S. Waara, B. Allard, T. von Kronhelm, and P. A. W. van Hees, "Laboratory and pilot scale soil washing of PAH and arsenic from a wood preservation site: Changes in concentration and toxicity," Journal of Hazardous Materials, vol. 172, pp. 1033-1040, July 2009.

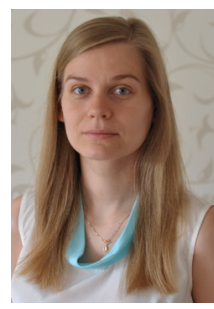

L. Timma was born in Krāslava, Latvia on March 16 , 1989. Timma is a last year's double diploma student in environmental engineering master degree program at the Riga Technical University and Vilnius Gediminas Technical University. She received the bachelor degree in environmental engineering in the Institute of Energy Systems and Environment in the Faculty of Power and Electrical Engineering at Riga Technical University in 2011 in Riga, Latvia. Her major fields of study are renewable energy systems, energy efficiency and

hazardous waste.

She works as a scientific assistant in Riga Technical University in the Institute of Energy Systems and Environment and as a researcher in the Competence Centre of Environment, Bioenergetics and Biotechnology in Riga, Latvia. She has taken part in Erasmus mobility program in the Royal Institute of Technology, Stockholm, Sweden. She has worked as the assistant of project manager in the Baltic Sea Region project "PlasTEP" and also taken part in the European Economic Area Financial Mechanism Program's subproject "Compact Solar and Pellet Module" and the Central Baltic 
Interreg IV A Programme's project "Energy Efficient and Ecological Housing". She is the co-author of more than 30 scientific publications.

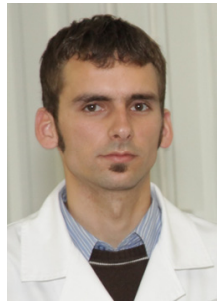

K. Sams was born in Latvia on January 23, 1986. Sams obtained the first level, higher professional education as an environmental technologist in the College of Mechanics and Technology in 2010, in Olaine, Latvia $\mathrm{He}$ acquired professional secondary education in Environment Technology in the College of Mechanics and Technology in Olaine, Latvia in 2007. The main fields of his study are cleaner production and environment protection technologies and environment monitoring.

He works in the company "Auravia Latvia" Ltd. as a process engineer. In "Auravia Latvia" Ltd, he is responsible for development of products, such as bio-based detergents and probiotics for various commercial applications including contaminated soil treatment. He has worked as an environment technician in the company which specializes in the design and installations of wastewater treatment plants, and as an environment technologist and the head of laboratory and biotechnological facility in waste management company. His main activities and responsibilities was the quality control, production of microbial products and the development of technology for microbiological remediation of polluted soils with oil products.

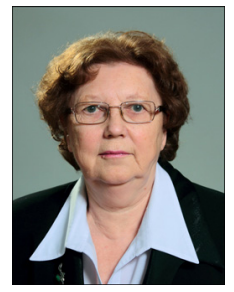

S. Valtere was born in Latvia on December 14, 1936. Valtere obtained the degree of doctor in Chemical Science in Riga Technical University, Riga, Latvia in 1992. Valtere has chemist diploma obtained from Latvian State University/Riga Polytechnical Institute in 1959, candidate of chemical sciences diploma in 1968, senior reseach scientist diploma in 1972 and associated professor diploma in 1985 from Riga Polytechnical Institute in Riga, Latvia. Her main research areas are environmental science and engineering.

She is a leading researcher in Riga Technical University, the Institute of Energy Systems and Environment. She is the expert for Environmental Management System Certification and an international expert for quality assesment in higher education. She has worked as the environmental consultant for Latvian Pollution Prevention Centre, as an associated professor for Riga Politechnical Instiute (later Riga Technical University), as the vice director of "EKOSAULE" Ltd. and as the dean for Riga Technical University Department of Postgraduate Education. She is the co-autor for more than 100 scientific publications, including 5 books and monographs in the fields of theoretical chemistry, cleaner production, environmental engineering, and environmental management

Dr.Chem.Valtere is a member of Latvian Chemical society and Federation of European Chemical Societies (FECS), a member of the Latvian Association for Waste Management and a member of Technical Committee of Environment Quality Management (ISO/IEC St. 14001) in Latvia.

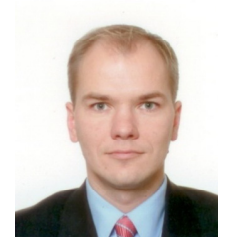

J. Vilgerts was born in Riga, Latvia on June 27, 1970 Vilgerts is fist year's Ph.D. student at Institute of Energy Systems and Environment, Riga Technical University. Vilgerts obtained master's degree in Public Administration (MPA) work, "Economic methods and tools for environmental policy" in the Faculty of Management and Economic Informatics, the University of Latvia, Riga, Latvia in 1997. His main research areas are hazardous waste management and cleaner production and environment protection technologies.

$\mathrm{He}$ is a member of Council in the Competence Centre of Environment, Bioenergetics and Biotechnology, the chairmen of Supervisory Board for JSC "BAO" and a member of Supervisory Board for "Vides pakalpojumu grupa". He has worked as the parliamentary secretary for the Ministry of Environment, as the chairman of the Board for the Coordination Council of Geodesy and Cartography and as a councillor for Latvian Council for Sustainable Development.

MPA Vilgers is a member of Latvian Association of Waste Management Companies.

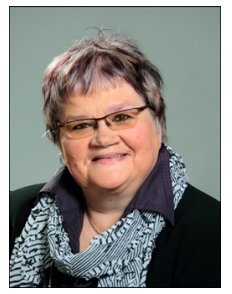

D. Blumberga was born in Latvia on August 1, 1945. Blumberga obtained thermal engineer diploma from Riga Technical University, Riga, Latvia, in 1970 and two steps doctoral degree diploma. Her Ph.D. thesis "Research of Heat and Mass Transfer in Gas Condensing Unit" was defended in the Lithuanian Institute of Energy in Kaunas, Lithuania, in 1988. Her Doctor Habilitus Thesis "Analysis of Energy Efficiency from Environmental, Economical and Management Aspects" was prepared in the Royal Institute of Technology (KTH) in Stockholm, Sweden in 1995 and was defended in Riga Technical University in Riga, Latvia in 1996. Her main research areas are renewable energy resources, demand side management, climate technologies and cleaner production.

She is a professor at Riga Technical University the Institute of Energy Systems and Environment and the director of the Institute of Energy Systems and Environment. She is the expert in Environmental Science at the Latvian Academy of Science and the European Commission Expert. She has worked as the lecturer in Latvian Post Graduate Institute for Specialists of Enterprises. She has participated in various local and international projects, for example, Intelligent Energy Europe project: Promotion of the Passive House Concept to the European Building Market, Nordplus cooperation Project: Education as an Essential Constituent of Bioenergy Policy in the Baltic Sea Region, Nordic Energy Research Programm NordCO2-CO2 sequestration. She is the co-author of more than 200 publications and 14 books.

Dr. D. Blumberga is a member of the Latvian heat, gas and water supply association, member of the Latvian Scientist community, member of the Latvian Environmental Science and Education Council, and the president of the Latvian biomass association. 